\title{
Barriers of Intraprenurship Practice at South African Public Hospitals: Perspectives of Unit Nurse Managers
}

\author{
Thandiwe Marethabile Letsie ${ }^{1}$ \\ ${ }^{1}$ Bloemfontein Free State, South Africa \\ Correspondence: Thandiwe Letsie, Bloemfontein Free State, South Africa. Tel: 27-51-833-793-156
}

Received: December 17, 2020 Accepted: January 20, 2021 Online Published: February 9, 2021

doi:10.5539/gjhs.v13n4p1 URL: https://doi.org/10.5539/gjhs.v13n4p1

\begin{abstract}
The paper highlights the barriers of intrapreneurship practice experienced by unit nurse managers working within the embattled public hospitals. The qualitative study was, descriptive, explorative and contextual in nature. The focus groups'discussions shed light on the plight of front runners constantly experiencing numerous intrapreneurial barriers frustrating ideation into implementable transformative programs. The barriers identified in this study include; lack of resources, security issues affecting freedom of staff and patients, poor staff ratios impacting on the rights of staff and patients, poor communication and unfair incentivised performance management system. The minimal conceptualization of intrapreneurship being quite foreign to nursing revealed in the findings is a wakeup call for senior teams pressured to improve performance. A number of public hospitals reforms consider the salient contribution of human capital in health care being key in driving quality improvement initiatives. Capacity development measures in education and clinical practice is a sensible recommendation through empowering nurses on business inclined management strategies like intrapreneurship practice improving the health care outcomes.
\end{abstract}

Keywords: barriers, public hospitals, intrapreneurship practice

\section{Introduction and Background}

The large public sector organizations inclusive of hospitals experiencing numerous challenges are mandated to constantly integrate business approaches like intrapreneurship, aimed at improving public value (Malatjie, Garg, \& Rankhumise, 2017). Intrapreneurship is a business inclined program supported by senior management within any company, where a culture of constant experimentation and innovation by intraprenerial teams/individuals culminates in development of new products, services, technologies, administrative techniques, strategies and competition (Ekiman, Korkmazer, \& Ekemen, 2018). The pro-active approach key in initiating reforms, generates alternative revenues, improves internal processes and develops innovative solutions to address social and economic needs. A positive intrapreneurial culture within public hospitals allows teams to offer effective, efficient and flexible services through integrating new technologies offering client-centred care to new health care consumer (Yonder Wise, 2014; Raadabai, Fayaz-Bakhsh, Nazari, Mousavi, \& Fayaz-Bakhsh, 2014). Therefore, survival of any hospital depends on; managers' strong leadership strategies, improved level of competency, ability to share values and cultures promoting intraprenurship practice within teams (Heinonen, Hytti, \& Eava, 2013). This paper supports the relevance of intrapreneurship at South African public hospitals and ponders on barriers encountered by public hospitals' unit nurse managers to incorporate reformatory intrapreneurial approach.

Extensive literature accents to the existing complexity of large public sector institutions due to numerous challenges they constantly face influencing the outcome of care (Kumar \& Pathak, 2017). Some of the intrapreneurship barriers experienced by public sector institutions include: risk of failure, bureaucratic system, lack of clarity of organizational goals, poor communication, resistance to change, rigid rules and regulations, lack of resources especially relevant human capital, lack of time, lack of organizational support, internal organizational politics, lack of motivation, reward or appropriate compensation methods, lack of seed funding towards intrapreneurial projects (Kumar \& Pathak, 2017). In intrapreneurial organizations, the existing barriers are not a setback. Instead, the unique attributes of an intrapreneurial unit nurse managers leading teams enable them to creatively bring in meaningful initiatives, improving services offered Deloitte University Press, 2013; Wilson \& Whitaker, 2012).

Intrapreneurship as the practice of entrepreneurship within an existing organization is gradually gaining popularity 
within the highly regulated nursing profession (Gifford Pinchot, 1985). The system oriented principle relevant in health care, endorses collaborative practice between senior management and outstanding individuals/teams not satisfied with status quo. The enabling culture of experimentation at public hospitals allows the intrapreneurial unit nurse leaders to spear head risk-taking innovative projects to improve internal processes (Kumar \& Pathak, 2017); (Wilson \& Whitaker, 2012). However, the following barriers preventing successful implementation of intrapreneurial practice include: operational difficulties, insufficient planning, unrealistic expectations insufficient organizational support and miscalculation of markets (Ekingen et al., 2018).

The contribution of a nurse intrapreneur, who is a salaried employee participating in health reforms plays a salient role in leading health care reforms (Wilson \& Whitaker, 2012). The creative and innovative nurse relentlessly considers new approaches aimed at improving delivery of services (Wilson \& Whitaker, 2012). This business inclined nurse, translates health care plans into implementation through integrating cost effective approaches enhancing and driving existing quality improvement programs (Wilson \& Whitaker, 2012). Meaningful initiatives are quite instrumental in informing the future of a progressive public hospital towards improvement of policy and capacity development on intrapreneurial principles to the entire nursing teams (Wilson \& Whitaker, 2012).

Most intraprenuership barriers highlighted by nursing scholars are personal and organizationally inclined. Extensive integrative literature by nurses across the globe highlighted the following barriers; authoritative leadership, conventional education focusing on patient management instead of organizational management, ethical and cultural conflicts in which the motive of profit making contradicts the professional values, unprecedented hierarchies in health care where doctors are overrepresented in policy, lack of business skills, lack of support from colleagues, rigid stereotypical lenses on the relevance of integrating economic perspective onto nursing practice, absence of collaborative initiatives interdepartmentally, lack of supporting policies, lack of monetary resources to support innovative initiatives, stringent power and control structures and cultural resistance to change (Collichi, e Lima, Bonini \& Lima, 2019; Wilson \& Whitaker, 2012; Brodtkorb, Skaar \& Slettebo, 2019; Deloitte University Press, 2013).

The significant contribution of an intrapreneurial unit nurse manager, with outstanding clinical skills who has acquired graduate education, is necessary to inform policy and improve delivery of health services. The unique nurse leaders operate at an advanced cognitive level enabling them to integrate intrapreneurial strategies to tackle any challenge sensibly (Wilson \& Whitaker, 2012). The business inclined preparation of nurse outside the conventional clinical model, enables them to apply a high set of knowledge and skills and address daunting health care challenges more scientifically (Wilson \& Whitaker, 2012). Some of the following set of attributes epitomising the outstanding nurse include; confidence, courage, integrity, self-discipline and risk-taking. The outstanding advocacy role enables them to solicit audience from peers and other relevant stakeholders locally and internationally through excellent communication skills (Wilson \& Whitaker, 2012). A leader, who is value-led, embraces a number of contemporary leadership and management approaches and overcome daunting barriers affecting intrapreneurship practice within complex public hospital spaces confronted with numerous challenges. This high calibre, unit nurse manager is highly valued by reforming public hospitals (Gilson \& Daire, 2011; Wilson \& Whitaker, 2012).

The numerous reforms put in place by the South African government geared towards universal coverage address the existing disparities in meaningful access to all South Africans through embodying National Health Insurance (NHI). Some of the progressive programs initiated by the government preparing full implementation of NHI initiative by different stake holders across the country include; Re-engineering of Primary Health Care, Ideal clinic/hospital and office of National Core standards facilitating accreditation of health care facilities (South Africa Department of Health, Ideal Hospital Realization and Maintenance framework manual, 2018). However, the poor leadership has been one of the key stumbling blocks for successful implementation of reforms (South Africa Department of Health, Ideal Hospital Realization Maintenance Framework, Manual, 2018) (Gilson \& Daire, 2011). The systems inclined intrapreneurial process becomes a meaningful turnaround management strategy to improve the health care outcome (Wilson \& Whitaker, 2012).

Transformation of organizational processes at public hospitals is highly dependable to senior management support. Lack of buy-in from senior management becomes a notable impediment affecting incorporation of intrapreneurship principles (Broomberg, 2011). The influential role of the senior teams is a crucial determinant in steering organizations they lead to greater heights through decentralization of power (Kan, Budhwani, \& Shaikh, 2011; Nel et al., 2008; Antoncic \& Antoncic, 2011). As a result, adoption of a more inclusive approach allows effective transfer of authority to the middle and frontline managers. The outstanding communication skills position them as efficient representatives of peers on the ground through their ability to discuss innovative ideas 
convincingly with senior teams and request the necessary support (Deloitte University Press, 2013).

The public hospitals' bureaucracy promoting top-down dictatorship program with little or no input from staff at operational level contradicts the bottom-up approach, evident in intrapreneurial organizations (Kan et al., 2011); (Salarzehi \& Forouharfar, 2011). This setback becomes a serious impediment towards meaningful incorporation of the innovative principle (Kan et al., 2011; Salarzehi \& Forouharfar, 2011). The large size of these public institutions affects free flow of communication vertically and horizontally within the structure. The inherent poor communication channels and structural towers common in public hospital organizations tend to prevent the flow of important information between authorities and junior team members. Intrapreneurs should not have to violate policies or risk their career to try new ideas. Instead, senior management should assist agile teams bringing in innovative ideas to navigate organizational processes and procedures to realize meaningful change (Deloitte University Press, 2013). Improved communication interdepartmentally and outside enhances collaborative partnerships aimed at improving services (Kan et al., 2011).

Other internal intrapreneurial barriers at public hospitals include; gross mismatch in mental attitudes between management and potential intrapreneurial individuals. This results in management's failure to promptly sport any potential talent; outdated management styles that are not inclusive; the organization holding on employees who feel threatened by impending transformation, thereby preferring the status quo. The unsupportive senior management teams towards experimentation frustrates intrapreneurial teams to embark on innovation that brings change (Salarzehi \& Forouharfar, 2011).

The current public hospital work environment that is still more conservative and restrictive, usually led by older management being sceptical towards transformation, is not relevant anymore. The more restrictive policies and attitudes of senior management and staff defeat intrapreneurial efforts embarked upon by younger personnel through meaningful venture creation. Salarzehi and Forouharfar (2011) raise a concern that it is quite difficult for intrapreneurial teams working within risk avert environment, to write convincing proposals aimed at securing capital from any potential sponsor (Salarzehi \& Forouharfar, 2011).

The paper takes cognizance of the volatile context of South African public hospitals facing different challenges including highly communicable pandemic like Covid-19 as a relevant stage for integration of intrapreneurial approach equipping unit nurse managers with business skills to adequately address the pressing health care demands. The design of public hospitals in South Africa driven through district based Primary Health Care system offers accessible health care services to urban and rural communities through meaningful referral system (Ranchod, Burger, Drayer, Stewart, Adams, Carvounes, Smith, \& van Biljon, 2017). The expenditure in these public institutions constantly escalates due to emergency treatment of many other conditions including the current acute Covid 19 pandemic. This has a negative impact on the already stretched public hospital budget. The transformative unit nurse manager who is a risk-taker, pro-active and creative engages senior teams convincingly on alternative cost-effective innovative strategies adding value to services geared towards quality improvement (Collichi, et al., 2019; Deloitte University Press, 2013).

\section{Methods}

\subsection{Study Design}

Intrapreneurship principle improves the structure, culture, system and processes within a forward thinking organization through capitalizing on existing resources to improve services (Collichi et al., 2019). The inductive and complex nature of qualitative studies allows researchers to paint a holistic picture of a phenomenon of interest (Burns \& Grove, 2012). The explorative, descriptive and contextual qualitative study enabled the researcher to clarify intrapreneurship barriers constantly experienced by unit nurse managers challenging their potential to embrace intrapreneurship as ideal strategy that could bring meaningful change (Botma, Greef, Mulaudzi, \& Wright 2010; Polit \& Beck, 2012; Pasque \& Lechuga, 2016).

\subsection{Study Setting}

The natural setting is quite crucial to the qualitative enquirer/constructivist who gives subjective interpretation on a phenomenon at hand within the context of the study (Creswell, 2014). The three public hospitals located in Bloemfontein, Free State offer different services, from simple to those demanding advanced specialized evidence based care. The interactive focus groups' discussions were conducted at private venues within the premises of each public hospital. 


\subsection{Population and Sampling}

One hundred and four-unit nurse managers working at the three public hospitals concerned in the study constituted the population of the study. A non-probability purposive sampling technique was used to select the participants. Forty-two-unit nurse managers available, participated in the focus groups' discussions (Burns \& Grove, 2009).

\subsection{Data Collection}

Focus group discussions being interactive in nature, were guided by some of the following principles; at each hospital, groups of about 6-10-unit nurse managers participated in the discussions, lasting about 2 hours. The principles relevant to focus groups considered include; homogeneity and other group dynamics preventing any bias ensured equal participation (Burns \& Grove, 2009). The discussions facilitated by an experienced qualitative researcher convened at a selected venues culminated in rich verbatim. Briefing exercise done by the facilitator, clarified the purpose of the study to the participants and those agreeing to participate signed the consent form. About five focus groups conducted in English were tape-recorded. The facilitator leading the discussions used this question: What are the existing intrapreneurship barriers at this public hospital where you work? Different interviewing techniques like probing, reflection paraphrasing and so on shed more light. The field notes taken during focus groups highlighted gestures, and different body language (Netshiswinzhe \& Mulaudzi, 2015). After each focus group session, debriefing was done, and any outstanding issue not clear was clarified. The discussions continued till no new information was elicited from the participants and this was a sign that data saturation was achieved (Botma et al., 2010).

\subsection{Data Analysis}

In the analysis of vast qualitative data, the reflective remarks of the participants are considered and field notes further assist the researcher to improve the quality of data elicited (Creswell, 2014). The following eight steps of Tesch qualitative data analysis technique were used:

Table 1. Qualitative data analysis by Tesch

\begin{tabular}{ll}
\hline$\bullet$ & The researcher transcribed data; \\
\hline$\bullet$ & Careful reading of transcriptions; \\
\hline$\bullet$ & The identified and similar topic were merged into major topics; \\
\hline & $\begin{array}{l}\text { Emerging topics were abbreviated according to codes and written next to the appropriate segment of the text, the popular } \\
\text { descriptive wording of topics was turned into major themes/categories; }\end{array}$ \\
$\bullet$ & Related topics were grouped together to diminish a list of categories; \\
\hline & $\begin{array}{l}\text { Final decisions on codes of categories were made and codes were written in a sequential order; and a preliminary analysis } \\
\text { fitted each category (Creswell, 2014). }\end{array}$ \\
\hline & $\begin{array}{l}\text { A co-coder analysed data independently. Afterwards, the researcher and the co-coder met and agreed on themes and } \\
\text { categories. }\end{array}$ \\
\hline
\end{tabular}

\subsection{Trustworthiness}

Trustworthiness of findings to a qualitative inquirer upholds similar principles of reliability and validity of the data preferred in quantitative designs (Lincoln \& Guba, 2004). Multiple validity strategies considered by the qualitative researcher in this study include; triangulation of data, member checking, use of rich, thick description of data, clarification of bias through self-reflection to create open and honest narratives, negative or discrepant information compared with authentic information, spending prolonged time, peer debriefing and use of external auditor (Creswell, 2014). The four principles of trustworthiness considered in this study include; credibility, confirmability, dependability and transferability.

\subsection{Ethical consideration}

Prior commencement of the study, permission was granted by appropriate institutions. The researcher took cognizance of the following ethical principles to protect the participants: justice, beneficence and confidentiality.

\section{Results}

Extensive literature brings forth a number of intrapreneurial barriers existing in large public sector organization. They include some of the following issues; vagueness of goals, constraints placed on managements' autonomy, 
over cautious managerial behaviour, reward system discouraging risk-taking, existing constrictive.

In this study, four themes emerging in the focus groups' discussions include: infrastructure; resources; security; communication; rights and incentives.

Table 2. Themes and sub-categories on unit nurse managers' perspectives regarding intrapreneurship barriers at South African Public hospitals

\begin{tabular}{|c|c|}
\hline THEMES & SUB-THEMES \\
\hline \multirow{2}{*}{ 1. Infrastructure } & 1.1 Run-down building, poorly maintained \\
\hline & 1.2 Slow building works \\
\hline 2. $\quad$ Resources & 2.1 lack of resources -material and human \\
\hline 3. $\quad$ Security & 3.1 Poor security at some hospitals \\
\hline \multirow{3}{*}{ Communication } & 4.1 Poor feedback from management \\
\hline & 4.2 No involvement of lower cadres \\
\hline & Resulting in poor implementation of policy \\
\hline 5. Rights & 5.1 Infringement of rights of nurse/patients \\
\hline 6. $\quad$ Incentives & 6.1 Performance management system \\
\hline
\end{tabular}

\subsection{Infrastructure}

The current ageing infrastructure poorly maintained, slow building works at South African public hospital becomes a pressing concern jeopardizing desired quality at public hospitals (Ranchod et al., 2017).

One participant raised the concern of poor infrastructure existent at public hospitals:

...... "Within the hospital facility for example the roof leaks for more than 6 months not before being repaired." (Participant B \# 2)

One participants raised a concern that the current interdepartmental procedure for reporting maintenance work to the building structure internally and in liaison with public works tends to be quite lengthy and delays repairs in their units.

The existing inter-departmental liaison between the Department of Health and Public works causes delays compromising the envisaged quality of services." (Participant B \# 2)

\subsection{Resources}

Management of public hospital covers day-to-day responsibilities involved in supporting and ensuring safe delivery of safe effective patient care, including management of human resources, finances, assets and consumables and information risk. Hospital resources range from; assets, funds, supplies, materials, stocks, staff and reserves. Available resources enable creative teams to continuously embark on novel projects changing processes and outcome of care (South African National Core standards, 2011).

The participants raised the concern of lack of resources becoming a serious barrier towards meaningful delivery of quality nursing care. The following resources lacking include: finances, staff and shortage of equipment.

..."Lack of funds is a big challenge at our hospital due to Provincial budget cuts or poor financial management by different levels of management making it difficult to pay salaries. " Participant $\mathrm{C} \#$ 5)

Participants considered the lack of resources in their hospital as a major obstacle in reaching their innovative potential.

One participants voiced the following financial concerns:

It becomes more difficult to employ more staff due to gross budget cuts. " Participant C \# 5)

One participant also highlighted the issue of staff shortage;

When one requires a certain number of professional staff, they have to wait for the end of the financial year to submit staff requisition, which is sometimes declined." (Participant C \# 5)

The participant emphasised that the existing lack of material resources at public hospitals is associated with 
stringent budget due to high financial regulation.

“....As a unit manager sometimes one needs equipment. However, it becomes difficult to purchase consumables due to budgetary constraints." (Participant C \# 5)

\subsection{Security}

The security in public hospitals ensures that people and property are protected from any possible threat. Lack of adequate security in some public hospitals puts staff and patients at risk. Health care workers across the country still experience armed robberies, murder and rape (South African National Core standards, 2011).

One participant raised a concern on the inadequately trained security acting slower, and not being alert to any potential threat of intrusion into the hospital:

"The securities who are not adequately trained about control measures. For instance, closing extra access into the hospital is necessary. Opening only major entry points into the hospital is sensible." (Participant B \# 4)

The urgency in tightening security at public hospitals to protect staff and patients was highlighted by one participant who emphasised that:

"The issue of tightening security is very important. For instance, one night at one of the three public hospitals, the intruder got into one of the units and a doctor on call was raped due to absence of a security at main points." (Participant B \# 2)

\subsection{Communication}

The large size of public hospitals and high bureaucracy affects proper flow of communication between different organizational hierarchies. Excellent channels of communication usually improve relationships between various groups, such as supervisors, subordinates, employee groups and the employer at large public hospitals (Nel et al., 2008).

One participant raised the concern of poor communication to junior teams by senior management;

"A lot of decisions are taken by management. So lower categories are not always included in key issues influencing the quality of work daily." (Participant A \# 2)

Another aspect raised was minimal involvement in designing protocols and guidelines

"The relevant teams not being included in the development of protocols and guidelines." (Participant A \# 2)

\subsection{Rights}

The extreme staff shortages currently experienced by the health care system creates gross infringement of rights of patients and the limited nursing staff handling diverse emergencies, communicable and non-communicable conditions (Muller \& Bester, 2017).

The nursing staff shortage is associated with a number of factors like; early retirement, excessive sick, leave possibly due to burn-out syndrome, low salaries compelling them to do part time in private sector (South Africa Health Review, 2017). The unpleasant scenario creates increasing pressure to the remaining pool of nurses to work extra hours.

The current immense staff shortages at public hospital affecting the normal delivery of care by nurses poses as a major violation of patients' rights. This was emphasised by one participant who said:

"In the dawn of democracy, one has heard more echoing of the patients' rights. Now patients are aware of their rights of receiving quality care. Therefore, their demands continue increasing despite limited work force." (Participant C \# 3)

Similarly, the existing gross staff shortages put so much pressure on remaining nurses and creates unpleasant nurse/patient ratios:

Seemingly, nurses' rights tend to be ignored too because they are expected to deliver quality care despite increasing responsibilities due high number of communicable and non-communicable diseases being treated in public hospitals." (Participant C \# 3)

\subsection{Incentives}

An incentive-based pay system applicable to individuals or groups is usually performance-based (Nel et al., 2008). Occupation Specific Dispensation is one measure that has been adopted by the South African Department of health. It offers incentives to professional nurses with certain specialities such as; Primary Health Care, Advanced Midwifery to mention just a few. The incentive is not necessarily tailor-made to create a seed funding for creative 
and innovative projects embarked upon by intrapreneurial teams. One participant raised some of the following concerns regarding the disparity on the incentivised specialization scheme which has loopholes aggrieving other employees:

- "We do have incentives through Performance Management System and incentivised system through the Occupational Specific Dispensation (OSD). However, the scheme still has shortfalls and it is not benefiting everyone." (Participant C \# 3)

- For instance, there are some officials holding a specific speciality like Advanced Midwifery but not allocated in their areas of specializations". (Participant B \# 3)

○ "The existing shortage of staff results in nurses being placed non-speciality areas." (Participant C \# 3)

\section{Discussion of Findings}

The South African public health care is facing numerous challenges compromising the desired quality improvement initiatives. The escalating communicable and non-communicable disease and parallel health care system creates gross disparities in accessing quality health care (South African Department of statistics, General Household Survey, 2016). Health care reforms improving meaningful access to health care include some of the following measures; the Reengineering of Primary Health Care, ideal clinic/hospital and establishment of the office of National Core Standards and National Health Care Insurance focusing at universal coverage of care (Southafrica.info, 2016). A number of existing challenges in the South African health call for senior management of public institutions to consider transformative management strategies like intrapreneurship practice. The key barriers towards intrapreneurial practice highlighted by the unit nurse managers include; existing poor infrastructure and other resources, poor security, rights and incentives.

A number of challenges still confronting the public hospitals, include; poor hygiene and infection control measures, abuse and neglect of patients, poor levels of care, overcrowding of patients, poor resources inclusive of manpower and infrastructure and so on (Southafrica.info, 2016). The on-going renovations poorly managed as sign of aging infrastructure in some public hospitals, creates open corridors for too long (Southafrica.info, 2016). A participant affirmed that delays in maintenance of buildings, compromises envisaged quality. "The roof leaks for more than 6 months not before being repaired."

Public hospital environment in South Africa faces gross shortage of resources compromising administrative and other services being rendered. For instance, the gross shortage of nursing personnel is a major problem echoed at different platforms by health care stakeholders (South Africa Health Review, 2017). This setback is attributable to a range of factors such as; poor working conditions and relaxed policies allowing dual practice between public and private sector. This affects the desired quality of care rendered in public hospitals. The current poor nurse/patient ratio at public hospitals sitting at (1:4), tends to put immense pressure on the operational nursing staff who are constantly dissatisfied and thereof experiencing burn-out syndrome (Uys \& Klopper, 2013; South Africa Health Review, 2017).

The cumulative effects of human resource challenges culminate in highly compromised clients' care, escalating the number of litigations at public hospitals and further stretching the limited hospital budget. Such an embattled hospital work environment, fails to nurture any existing creative and innovative talent (Dayhoff \& Moore, 2002). The existing staff shortage compromises care. This was echoed by one participant who said; "It becomes more difficult to employ more staff due to gross budget cuts."

Safety at public hospital institutions becomes a more holistic perspective taking cognizance of the general welfare of staff, patients and communities (Muller \& Bester, 2017). The government initiatives place emphasis on positive practice environment in private/public health care institutions, prioritize principles promoting pro-active strategies ensuring that organizational and patients' outcomes are met (Muller \& Bester, 2017). The environment has to be safe, caring, healing, humane, respectful of people's rights, responsibilities, needs and contributions. The crucial administrative aspects to be considered in ensuring safe working spaces take heed on different aspects like; safety, wellbeing of staff, quality patient care, improvement of motivation, productivity of individuals and organization integrated in quality improvement program are upheld to achieve excellent health care delivery (Muller \& Bester, 2017). The compromised safety at the public hospital due to poor management and leadership is an urgent call requiring intrapreneurial front-runners to constantly see existing challenges compromising safety of patients, staff and communities as potential hub for creativity and innovation to improve delivery of services in the future. "The securities who are not adequately trained about control measures. For instance, closing extra access into the hospital is necessary.

Some of the rights endorsing client-centred care enhancing informed decision-making by clients consider; 
promotion of a healthy and safe environment; participation in decision making; access to health care, knowledge of one's health and so on (Muller \& Bester, 2017). A wider public audience from civil society, statutory bodies like boards incorporating representation from members of communities should constantly discuss issues that could compromise quality like, inadequate risk management initiatives. Therefore, it is mandatory for strategic leaders to constantly take heed of external environmental trends impacting on internal processes and outcomes of care (Muller \& Bester, 2017). The participants acknowledged the patients' knowledge of their rights and concerns regarding the hostile work environment compromising quality. "Now patients are aware of their rights of receiving quality care."

Similarly, the nursing staff as key participants in the delivery of quality health care are controlled by professional regulatory organization/organized labour bodies (Muller \& Bester, 2017). So it is essential for the health division manager to be acquainted with the rights of professional service providers to protect nursing teams (Muller $\&$ Bester, 2017). The participants are aware of staff's rights. However, the pressing challenges due flawed administrative processes are quite concerning and create teams which are risk avert. "Seemingly, nurses' rights tend to be ignored too because they are expected to deliver quality care despite increasing responsibilities".

Existing bureaucracy common to large public hospitals causes serious communication concerns between different hierarchies. Open lines of communications at rigid public hospitals are essential to improve communication at different levels. In intraprenerial organizations, decentralization of power results in flatter and flexible structures like adhocracy being project oriented, thereof preferred. This enables better integration of teams interdepartmentally or externally through collaborative innovative efforts aimed at improving services. Easier lateral and vertical communication of different levels allows timeous feedback to different employees. (Kan et al., 2011; Nel et al., 2008; Antoncic \& Antoncic, 2011). The participants highlighted the existing poor communication between different levels as a serious concern since, in most instances, they are excluded on administrative decisions influencing operations; for instance, "A lot of decisions are taken by management. So lower categories are not always included in key issues influencing the quality of work daily."

Lack of a good reward system or seed funding on innovative initiatives is one of the key barrier frustrating any prospects of incorporating intrapreneurship principle reputable for improving performance through creation of new business ventures at public hospitals (Antoncic \& Antoncic, 2011). The incentivised program of Occupation Specific Dispensation in South Africa offers incentives to certain specialities and meets a lot of internal criticism due to its unfairness. In this study, existing inconsistency in Occupation Specific Dispensation incentives where nurses holding similar specializations were not given the incentives because the applicable speciality areas were full. At times, some of the qualified professional nursing staff were placed in non-speciality areas. The shortfall was highlighted by one participant who said; "We do have incentives through Performance Management System and incentivised system through the OSD. However, the scheme still has shortfalls and it is not benefiting everyone."

The existing day to day challenges confronting the front-line leaders at the struggling public hospitals is a cause for concern. The findings highlight the existing concerns compromising envisaged performance at public hospitals as overwhelming to the unit nurse managers who constantly have to uphold the set policies and standards despite inundated with challenges like scarce resources, bureaucracy, poor communication, environmental influences and so on. The absence of intrapreneurship practice, bringing business acumen in solving existing challenges by front-leaders is concerning. The poor synergy between external and internal environmental influences reflected in findings shows insufficient business preparation and the bigger perspective of macro/micro economic impact significant in improving business processes.

A notable limitation on the findings highlights the existing poor synergy between operational and senior teams on the possible turn-around strategy considering a bottom-up and top-down approach achievable through sustainable intrapreneurship approach. The inclusive approach unites the entire organization. The positive business perspective, considers these public hospital environments as a hub for research calling for proper integration of evidence-based practice, and technology-based care to improve the quality of care.

Another interesting shortfall on the findings is lack of clarity on the type of a leader the unit nurse manager reflects. Unanimously nursing scholars consider transformational leadership and other democratic styles, ideal in reforming the embattled public hospitals. Attributes of a transformational leader embody the intrapreneurial unit nurse manager who is a visionary and motivates followers towards espousing good work ethics and integrity (Gilson \& Daire, 2011). The highly charismatic leader who is a visionary, intellectual stimulator and a mentor constantly inviting intrapreneurial junior teams to buy-into their strategic vision (Gilson \& Daire, 2011). 


\section{Conclusions}

The complex nature of health care organizations calls for nurses who constantly learn to stay abreast through incorporating new knowledge that assists public hospitals to integrate new technology which improves the delivery of services (Yonder-Wise 2014). Learning public hospital organizations need to provide numerous incentives to the nurses through incorporating collaborative partnerships with internal/external stakeholders (Wilson \& Whitaker, 2012). The significant number of nurses at public hospitals is advantageous and their notable presence makes a notable contribution through changing public hospitals culture towards intrapreneurial innovation. The adoption of new contemporary leadership approaches by unit nurse managers, unleashes innate business inclined characters enabling them to be resilient and integrate strategic approaches to overcome a number of existing intrapreneurial barriers frustrating potential reforms at public hospitals.

\section{Recommendations}

The findings of this paper shed light on the daunting barriers on intrapreneurship practice experienced by unit nurse managers at South African public hospital environment inundated with numerous challenges. The forward-thinking public hospitals adopt cultures enabling outstanding teams to creatively bring in desirable change. Public hospitals being under constant pressure, need to deliver services offering greater value to a diverse clientele base from different backgrounds. Alignment of mission, market positioning, service line portfolio of the public sector with the private sector improves integration of future progressive innovative projects improving the delivery of services.

\subsection{Improving Clinical Practice}

- Intrapreneurship as a principle of reform requires more audience from all the relevant stakeholders within the profession and outside.

- It is necessary for senior management to adopt a collaborative approach with lead nurse intrapreneurs to mentor younger upcoming nurses on project oriented innovative improvements.

- Creating a seed fund for innovative initiatives is sensible. This allows intrapreneurial teams/individuals to constantly develop new projects.

- Transformation of the workplace culture is an urgent matter requiring more attention by the authorities concerned through turning these depressing public hospital environments into intrapreneurial platforms. This enables teams to embark on non-punitive risk-taking initiatives that could bring potential improvement in the delivery of services.

\subsection{Research}

- A collaborative approach through more research publications with civil society to a wider local and international audience, creates a synergy improving the different scholarships of; research, teaching and learning through on-going partnerships with service and academic institutions.

- Constant capacity development intrapreneurial programs at different levels of management offers a paradigm shift on conventional nursing, predominantly focusing on clinical aspects of care.

\subsection{Education}

- The development of a business inclined curriculum calls for a collaborative multidisciplinary approach embracing members of civil society, the business communities and Faculties of Business Economics, Management Science and Public Administration through integrating the principles of an adult learner.

\section{Limitations of the Study}

- Intrapreneurship principle being a foreign concept to nurses

- Inconsistency of the sizes of the focus groups at different settings.

- Some participants dominating the discussions while others had minimal or no participation.

- Difficult to get appointments at different hospitals with heads of clinical services and unit managers who were absent due to other commitments like; in-service training, night duty and so on.

\section{Competing Interests Statement}

The author declares that there is no competing or potential conflict of interests.

\section{References}

Antocic, J. A., \& Antoncic, B. (2011). Employee satisfaction, intrapreneurship and firm growth: a model. Emerald, 
11(4), 589-607. https://doi.org/10.1108/02635571111133560

Botma, Y., Greeff, M., Mulaudzi, F. M., \& Wright, S. C. D. (2010). Research in health Sciences. Pearson Education (Pty) Ltd. Cape Town.

Brodkorb, K., \& Skaar, R. S. (2019). The importance of leadership and innovation. Retrieved from https://www.us.no/en/kk/prof/ash.ds.

Broomberg, J. (2011). Solving health care challenges in South Africa. Retrieved from http://www.leader.co.za/article.aspx?s=1\&f=1\&a-2980.

Burns, N., \& Grove, S. (2009). The practice of nursing research, appraisal, synthesis and generation of evidence (6th ed.). Saunders, An imprint of Elsevier Inc Missouri.

Colichi, R. M., eLima, S. G., Bonini, B. B., \& Lima. (2019). Integrative review. Entrepreneurship in Nursing. https://doi.org/10.1590/0034-7167-2018-0498

Creswell, J. W. (2014). Research design qualitative, quantitative and mixed methods approaches, (4th Edition). California, United States of America. Sage Publications. Retrieved from https://researchskillsgmm.files.wordpress.com/2014/10/research-design-creswell-chapter9.pdf

Dayhoff, N. E., \& Moore, P. S. (2002). Entrepreneurial clinical nurse specialists: Innovators of patient care. Clinical Nurse Specialist, 16(5), 274-276. https://doi.org/10.1097/00002800-200209000-00012

Delloitte Digital. (2015). Five Insights into Intrapreneurship. Retrieved from www. Deloitte.com/de/UeberUns

Ekingen, E., Ekemen, M. A., Yildiz, A., \& Korkmazer, F. (2018). The effect of intrapreneurship and organizational factors on the innovation performance in hospital. Revista de Cercetare si Interventie Sociala, 62, 196.

Gilson, L., \& Daire, J. (2011). Leadership and governance within the South African health system. South African health review, 2011(1), 69-80. Retrieved from http://reserachchonline.Ishtm.ac.uk/1082607/.

Heinonen, J., Hytti, U., \& Vuorinen, E. (2013). Intrapreneurial risk-taking in public healthcare: challenging existing boundaries. In Entrepreneurial business and society. Edward Elgar Publishing.

Khan, B. A., Budhwani, Z. R., \& Shaikh, A. (2011). Practicing intrapreneurship: a case of service- sector firms in Pakistan. Journal of Management and Social Sciences, 7(1), 0-11. https://doi.org/10.1016/j.sbspro.2011.05.101

Kumar, R., \& Pathak, G. S. (2017). Barriers of Intrapreneurship in organizations: Literature review. Retrieved from http://hgl.handle.net/1234567089/5937

Laissani, V., Antoncic, B., Antoncic, J. A., \& Aydinlik, A. U. (2012). Organizational values and firm growth: Evidence of Turkey. EuroJournals Publishing, Inc. Retrieved from $\mathrm{http} / / / \mathrm{www}$. middleeasterneconomicsandfinance.com.

Lincoln, Y., \& Guba, E. G. (2004). Trustworthiness and authenticity in naturalistic evaluation. https://doi.org/10.1002/ev.1427

Malatjie, I., Garg, A., \& Rankhumise, E. (2017). Corporate entrepreneurship in the public sector: a South African perspective. International Conference on Public Administration and Development Alternatives (IPADA). Retrieved from U/space.u.ac.za/.../10386/1834

Muller, M., \& Bester, P. (2017). Nursing dynamics. (Pearson 5th ed.). Cape town, South Africa.

Nel, W., Haasbroek, G. D., Poisat, P., Sono, T., \& Schultz, H. B. (2008). Human resource management (7th ed.). Cape Town, South Africa. Oxford University Press.

Netshiswinzhe, M. D., \& Mulaudzi, F. M. (2015). Perceptions of nurse educators regarding implementation of occupational specific dispensation at selected nursing college in Limpopo province. Health Gesondheid, 20(2015), 100-108. https://doi.org/10.1016/j.hsag.2015.04.003

Pasque, P. A., \& Lechuga, V. M. (2016). Qualitative inquiry in higher education organization and policy research. https://doi.org/10.4324/9781315619392

Polit, D. F., \& Beck, C. T. (2012). Nursing research. Generating and assessing evidence for nursing practice (9th ed.). Philadelphia, United States of America. Lippincott and Wilkin.

Price Water Coopers. (2015). Price Water Strategic Transformation solving the most Complex problems of providers and delivery systems. Retrieved from www.pwc.com 
Raadabadi, M., Fayaz-Bakhsh, A., Nazari, A., Mousavi, S. M., \& Fayaz-Bakhsh, M. (2014). Organizational Entrepreneurial and administrator of hospitals: Case study of Iran. https://doi.org/10.5539/gjhs.v6n3p249

Rego, A., \& Araujo, B. (2019). Ethics guiding the action of the hospital manager. Journal of Hospital Administration, 8(2), 14-20. https://doi.org/10.5430/jha.v8n2p14

Ranchod, S., Burger, R., Dreyer, K., Stewart, J., Adams C., Carvounes, A., ... \& van Biljon (2017). South Africa's hospital sector: Old divisions and new developments. Retrieved from https://journal.co.za/content/journal/10520/EJC-c80f3c5a8-Guqulela.

Salarzehi, H., \& Forouharfar, A. (2011). Understanding barriers to intrapreneurship in work and social affairs governmental organization. Interdisciplinary Journal of Contemporary Research in business, 2(12), 490-503. https://doi.org/10.2139/ssrn.2339673

South African Department of Health. (2011). Human resource Strategy report for health care sector, 2011. Pretoria: National Department of Health. Retrieved from http://www.doh.gov.za/docs/reports-f.html.

South Africa Department of Health. (2011). "Towards quality care of patients" National Core Standards for Health establishment in South Africa. Retrieved from http://www.doh.gov.za/docs/reports-f.html.

South Africa Department of Statistics. (2016). General Household Survey. Pretoria National department of Statistics. Retrieved fromhttp://www.statsa.gov.

SouthAfrica.info. (2016). Health care in South Africa. Retrieved from http://www.southafrica.info/about/health/health.htm.

South Africa Health Review. (2017). Celebrating 25 years of health systems Strengthening. Health systems Trust. Retrieved fromhttp://www.hst.org.za

South Africa department. (2018). Ideal hospital realization and maintenance framework manual. Retrieved from www.health.gov

Teddlie, C., \& Tashakkori, A. (2009). Foundations of mixed methods research. Integrating quantitative and qualitative approaches in the social and behavioral sciences. SAGE Publications Inc. California.

Uys, L. R., \& Klopper, H. C. (2013). What is the ideal ratio of categories of nurses for the South African public health system? South African Journal of Science, 109(5/6), 1-4. https://doi.org/10.1590/sajs.2013/a0015

Wilson, A., Whitiker, N., \& Whitford, D. (2012). Rising challenge of health care reform with entrepreneurial and intrapreneurial nursing initiatives. Online Journal issues in nursing, 17(2). Retrieved from https://doi.org/10.3912/OJIN.vol17N0o2Man05.

Yonder-Wise, P. S. (2014). Leading and managing in nursing (5th ed.). Missouri, USA: Elseveir.

\section{Copyrights}

Copyright for this article is retained by the author(s), with first publication rights granted to the journal.

This is an open-access article distributed under the terms and conditions of the Creative Commons Attribution license (http://creativecommons.org/licenses/by/4.0/). 